\title{
Estratégias de aprendizagem utilizadas por gerentes no desenvolvimento de suas competências em instituições financeiras
}

\section{Learning strategies used by managers in the development of their competences in financial institutions}

\author{
Sergio Santoro ${ }^{i}$ \\ Orcid: http://orcid.org/0000-0001-6651-7051 \\ Diógenes de Souza Bido ${ }^{\mathrm{ii}}$ \\ Orcid: https://orcid.org/0000-0002-8525-5218
}

\begin{abstract}
Resumo
As estratégias informais de aprendizagem no trabalho podem ser entendidas como práticas que as pessoas utilizam para auxiliar na obtenção de conhecimentos em um contexto profissional específico, e o desenvolvimento de competências, por sua vez, ocorre por meio da aprendizagem. Esta pesquisa tem como objetivo geral identificar as estratégias de aprendizagem no trabalho utilizadas por gerentes no desenvolvimento de suas competências em instituições financeiras pública e privada. O tipo de metodologia utilizado foi a pesquisa qualitativa interpretativa básica, e a coleta de dados se deu por meio de entrevistas semiestruturadas. Os resultados obtidos indicam que, tanto para os gerentes pertencentes ao banco público quanto para aqueles oriundos do banco privado, há uma preferência natural pela utilização da estratégia de aprendizagem "busca por ajuda interpessoal", pois recorrer a pares ou a superiores hierárquicos é mais prático e rápido.

Palavras-chave: estratégias de aprendizagem no trabalho; desenvolvimento de competências gerenciais; instituições financeiras.
\end{abstract}

\begin{abstract}
Informal learning strategies at work can be understood as practices that people use to assist in obtaining knowledge in a specific professional context, and the development of competences, in turn, occurs through learning. This research established as the general objective: to identify the learning strategies at work used by managers in the development of their skills in public and private financial institutions. The type of methodology was the basic interpretative qualitative research, and the data collection was carried out through semi-structured interviews. The results indicated that, both for the managers belonging to the public bank as for those from the private bank, there is a natural preference for the use of the learning strategy "interpersonal help seeking" as turning to peers or hierarchical superiors is more practical and faster.

Keywords: learning strategies in the workplace; development of managerial competences; financial institutions.
\end{abstract}

\footnotetext{
' Universidade de Coimbra, Portugal. E-mail: sergio_santoro@hotmail.com

ii Universidade Presbiteriana Mackenzie, Brasil. E-mail:diogenesbido@yahoo.com.br
} 


\section{INTRODUÇÃO}

De uma maneira geral, as empresas disponibilizam maior atenção e recursos aos meios formais de aprendizagem, que são constituídos por cursos de qualificação, treinamentos, programas de desenvolvimento, entre outros. No entanto, existem outras maneiras para promover $o$ desenvolvimento de competências, que não são ações formais de aprendizagem (FREITAS; BRANDÃO, 2006; LE BOTERF, 1999). As estratégias informais de aprendizagem no trabalho podem ser compreendidas como práticas que as pessoas utilizam para ajudar na aquisição de conhecimentos em determinado contexto profissional (HOLMAN et al., 2001, 2012).

As estratégias formais, de um modo geral, são planejadas pela empresa, enquanto as estratégias informais são utilizadas pelas pessoas como uma forma de resolverem algum problema mais imediato, assim, buscam ajuda interpessoal, ajuda em material escrito, agem por tentativa e erro (aplicação prática) ou reproduzem a forma com que os colegas agem em um processo ou situação (WARR; DOWNING, 2000).

$\mathrm{O}$ desenvolvimento de competências, por sua vez, acontece por meio da aprendizagem, quer seja de forma natural, formal ou informal (SONNENTAG; NIESSEN; OHLY, 2004). Durand (2000) relaciona a aprendizagem com a aquisição de conhecimentos, habilidades e atitudes. De acordo com essa compreensão, Brandão e Borges-Andrade (2007) argumentam que esses elementos podem ser considerados propriedades do indivíduo, ou seja, fatores que influenciam o comportamento no trabalho.

Mais especificamente, dos gerentes são exigidos, além de conhecimentos técnicos e do ambiente, habilidades e atitudes que lhes permitam agilidade e flexibilidade para agir de maneira diferenciada em relação a cada problema (RUAS, 2003). É esperado que possuam competências que lhes possibilitem lidar com a complexidade do meio empresarial, como por exemplo: comunicação e colaboração, criatividade, capacidade de resolver problemas, aprendizado tecnológico, atualização constante e autodesenvolvimento, o que implica em uma forte predisposição a aprender (ULRICH, 2000).

A escolha por comparar as estratégias de aprendizagem usadas por gerentes de banco público com as de gerentes de banco privado no desenvolvimento de suas competências se deu pelo fato de que os gerentes de bancos públicos ingressam nesse tipo de instituição por meio de concurso público, como por exemplo na Caixa Econômica Federal, onde os gerentes iniciam a carreira administrativa com o cargo efetivo denominado Técnico Bancário, ascendendo na hierarquia por meio de promoções por tempo de serviço e merecimento profissional; enquanto que os gerentes de bancos privados são recrutados e selecionados já como gerentes advindos do mercado profissional, como foi encontrado por Hito (2011).

Dessa maneira, os gerentes de bancos públicos possuem relativa estabilidade de emprego, diferentemente do que acontece com os gerentes de bancos privados, que são continuamente avaliados por desempenho para que permaneçam empregados nessas instituições.

Assim sendo, o objetivo deste artigo é identificar as estratégias de aprendizagem no trabalho usadas por gerentes no desenvolvimento de suas competências em instituições financeiras pública e privada.

\section{FUNDAMENTAÇÃO TEÓRICA}

\subsection{Estratégias de Aprendizagem Informal no Local de Trabalho}

Holman et al. (2001, 2012) postulam que as estratégias de aprendizagem no trabalho podem ser compreendidas como práticas que as pessoas utilizam para auxiliar a aquisição de conhecimento em determinado contexto profissional. Warr e Downing (2000) 
incluem no conceito de estratégias de aprendizagem atividades manifestas (processos comportamentais) e não observáveis (processos cognitivos e afetivos), que apresentam variação entre indivíduos e ambientes de aprendizagem e que são importantes para aperfeiçoar os processos de aprendizagem humana no trabalho.

Os autores utilizaram categorias que foram desenvolvidas anteriormente por Warr e Allan (1998) em um estudo conceitual e empírico, que apontou nove estratégias de aprendizagem distribuídas em três grandes categorias: cognitiva, comportamental e autorregulatórias.

De acordo com Warr e Downing (2000), as estratégias de aprendizagem cognitivas foram classificadas em três diferentes tipos: reprodução, organização e elaboração, que representam, respectivamente, procedimentos executados por meio da repetição contínua sem reflexão; procedimentos que criam estruturas mentais e interrelacionam elementos para a aprendizagem; e procedimentos que fazem conexões mentais entre o conteúdo a ser aprendido e o conhecimento existente.

Em relação às estratégias de aprendizagem comportamentais, Warr e Downing (2000) as classificaram em: busca por ajuda interpessoal, busca por ajuda em material escrito e aplicação prática. As estratégias de aprendizagem autorregulatórias foram classificadas em: controle emocional, controle da motivação e monitoramento da compreensão.

Holman et al. (2001) validaram uma escala de estratégias de aprendizagem em um contexto de trabalho, junto a empregados do call center de um banco britânico. Seus resultados encontraram as categorias relacionadas a seguir, sendo que as três primeiras constituem estratégias de aprendizagem cognitivas, enquanto as três últimas estão relacionadas às estratégias comportamentais - a) reprodução: repetição mental da informação, sem reflexão sobre seu significado; b) reflexão intrínseca: reflexão sobre as relações existentes entre as partes componentes do trabalho; c) reflexão extrínseca: reflexão sobre as relações entre o trabalho e diferentes aspectos da organização; d) procura de ajuda interpessoal: busca ativa do auxílio de outras pessoas; e) procura de ajuda em material escrito: pesquisa e localização em documentos, manuais, livros e outras fontes não sociais; e f) aplicação prática: tentativa de colocar em prática os próprios conhecimentos enquanto aprende.

Holman et al. (2012) também analisaram se as estratégias de aprendizagem informal funcionam como um mecanismo por meio do qual o design do trabalho impacta o processo de inovação dos empregados. Os autores confirmaram o papel mediador das estratégias de aprendizagem informal na relação entre o design do trabalho e a geração de ideias. Os efeitos de controle do trabalho na geração de ideias foram mediados por estratégias de aprendizagem informal baseadas no trabalho e os efeitos de demanda do problema sobre a geração de ideias foram parcialmente mediados por estratégias de aprendizagem informal (HOLMAN et al., 2012). Os estudiosos concluem que a criação de empregos com alto controle ou alta demanda de problemas pode ajudar a promover o processo de inovação dos empregados, e que isso se deve, em parte, ao papel que tais empregos desempenham no estímulo à utilização de estratégias de aprendizagem informal no trabalho.

De acordo com Sparr, Knipfer e Willems (2017), a busca de feedback e a reflexão são comportamentos de aprendizagem informal na transferência de treinamento formal em programas de desenvolvimento de liderança, ou seja, atividades de aprendizagem informal, como a busca de feedback e a reflexão, são fundamentais após a realização de um treinamento formal para a transferência do conhecimento, especialmente quando habilidades complexas são ensinadas, como a liderança. 
No Brasil, Pantoja (2004) validou uma escala de trinta itens sobre estratégias de aprendizagem, em uma amostra de profissionais de diversas ocupações. A autora encontrou cinco categorias distintas de estratégias, agrupando em um único fator os itens relativos às estratégias aplicação prática e reflexão intrínseca. Os demais fatores mantiveram semelhança com aqueles originalmente encontrados por Holman et al. (2001).

Já Antonello (2011) apresenta doze categorias de aprendizagem utilizadas por gestores no desenvolvimento de competências, conforme Tabela 1:

\section{Tabela 1: Categorias de aprendizagem utilizadas por gestores}

Categorias de Aprendizagem
Transferência de aprendizagem de ocupação/cargo anterior e aprendizagem fora do trabalho, por exemplo, trabalho voluntário.

Experiências amplas (requerem múltiplas habilidades e compreensão global) e experiências multifacetadas (requerem conexão entre diversas áreas de conhecimento), atividades pioneiras e de inovação, experiências traumáticas advindas de situações difíceis e processos de mudança organizacional, por exemplo, reestruturação ou fusão.

Experienciar

Reflexão sobre a ação (após atividade ou evento), reflexão na ação (durante uma

Reflexão atividade ou evento), reflexão em grupo/coletiva, questionamento e aprendizagem oriunda do fracasso.

\begin{tabular}{l}
\hline Autoanálise \\
\hline Observação-modelo
\end{tabular}
Referindo-se à autoanálise e à autoavaliação.

Observação estruturada e crítica dos outros, observação informal/casual dos outros, modelo de papel positivo, ou seja, tentar fazer algo como alguém faz, modelo negativo de papel, isto é, esforço para não fazer como alguém faz.

Feedback oriundo de sua equipe de trabalho, crítica de pares de trabalho, avaliação

Feedback de desempenho formal por pares/colegas/superiores, escuta eficiente para o que é dito sobre o desempenho, feedback oriundo de clientes e de outros profissionais e leitura da linguagem do corpo (como as pessoas reagem a você).

\begin{tabular}{ll}
\hline $\begin{array}{l}\text { Mudança de } \\
\text { perspectiva }\end{array}$ & $\begin{array}{l}\text { Mudança de papel, transferência/troca de trabalho, trabalhar com pessoas de áreas } \\
\text { diferentes, trabalhar com diferenças culturais e inspiração súbita ou insight. }\end{array}$ \\
\hline $\begin{array}{l}\text { Mentoria (mentoring) e } \\
\text { tutoria (coaching) }\end{array}$ & $\begin{array}{l}\text { Ser assistido por um mentor/tutor - mentor (orientador/conselheiro) e tutor } \\
\text { (treinador, que instrui e demonstra). }\end{array}$ \\
\hline $\begin{array}{l}\text { Interação e } \\
\text { colaboração }\end{array}$ & $\begin{array}{l}\text { Trabalho em grupo/equipe, colaboração em projetos, aprendizagem oriunda de } \\
\text { outros profissionais da mesma área, aprendizagem a partir de clientes, trabalho em } \\
\text { equipes multidisciplinares e rede (networking) com outros profissionais da mesma } \\
\text { área. }\end{array}$ \\
\hline Cursos e treinamentos & $\begin{array}{l}\text { Treinamento no trabalho (on the job), rotação de funções (job rotation) e programa } \\
\text { trainee, intensa aprendizagem/intenso treinamento (muito além do mínimo para um } \\
\text { desempenho competente), multiplicação de treinamentos/cursos. }\end{array}$ \\
\hline Informal & $\begin{array}{l}\text { Informal no trabalho (baseada na prática - aprendizagem informal e comunidade de } \\
\text { prática) e informal (em cursos de mestrado e especialização). }\end{array}$ \\
\hline
\end{tabular}

Aprendizagem pela Escrever artigos/relatórios, apresentar conferências, justificar/defender/explanar articulação entre teoria ações, trabalhos do curso, simulação durante curso, trabalho final e dissertação e e prática especialização/mestrado articulados à aprendizagem baseada no trabalho.

Fonte: Antonello (2011).

Para o presente estudo, as classificações das estratégias de aprendizagem informal no trabalho desenvolvidas por Antonello (2011) serão utilizadas para fazer a relação com o desenvolvimento de competências gerenciais que são listadas neste trabalho, pois, em seu estudo, Antonello (2011) 
encontrou mais categorias de aprendizagem utilizadas por gestores do que seus antecessores.

\subsection{Os Modelos de Competências Propostos por Cheetham e Chivers}

Cheetham e Chivers (1996, 1998, 2005) investigaram como profissionais, de diferentes áreas do conhecimento, aprendem e aprimoram suas competências profissionais e apresentaram, então, um modelo de competências. Para sua elaboração, utilizaram ampla gama de modelos existentes, protocolos para descrição de competências, extensa literatura sobre educação e desenvolvimento profissional e um estudo empírico que envolveu 80 pessoas de 20 diferentes profissões.

Segundo Cheetham e Chivers (1996), as visões existentes, isoladamente, não forneciam a base para a explicação do significado de competência com a abrangência requerida. Dessa maneira, integraram em seu modelo várias concepções, sendo as principais: a abordagem técnico-racional; a abordagem profissional-reflexiva; a abordagem de competência funcional; a abordagem de competência pessoal; as abordagens de ética; metacompetência; e transcompetências.

A abordagem técnico-racional considera que o profissional atua com base nos conhecimentos especializados ou técnicos, adquiridos pela aprendizagem formal. A fundamentação para a prática profissional está em sólidos conhecimentos teóricos, que dão origem à competência prática.

\section{A abordagem profissional-} reflexiva sofreu influências fundamentais do trabalho seminal de Schön (1983) ao assumir que a competência crucial para todas as profissões é a reflexão. Ela é importante para o desenvolvimento inicial, para a prática do dia a dia e para a melhoria contínua. Os tipos de reflexão incluem a reflexão em ação (durante uma atividade) e

reflexão sobre ação (após uma atividade). A abordagem profissional-reflexiva substituiu a visão tradicional de que os profissionais resolvem problemas usando o conhecimento técnico especializado e adquirido pela aprendizagem formal.

A abordagem funcional refere-se ao modelo de competência baseado nos padrões profissionais definidos pelo governo da Grã-Bretanha para todos os tipos de ocupações, inclusive as gerenciais, que são usados no sistema de Qualificações Vocacionais Nacionais (NVQs). A abordagem de padrões profissionais está fortemente baseada na noção de competência (JESSUP, 1991). A competência é identificada nos resultados do trabalho e seu foco está nas tarefas a serem executadas, no aprimoramento de habilidades genéricas fundamentais $\mathrm{e}$ habilidades específicas do trabalho.

\section{A abordagem comportamental} sofreu influência do trabalho sobre competência comportamental desenvolvido por pesquisadores norte-americanos, incluindo Boyatzis (1982), Klemp (1980) e Schroder (1989). Diferentemente da abordagem de competência funcional, vários pesquisadores dos Estados Unidos, particularmente no campo da Administração, focalizam nas competências pessoais ou comportamentais, tais como: a autoconfiança, o controle emocional e as habilidades interpessoais.

Outras dimensões foram identificadas como integrantes da competência profissional. A abordagem de ética e valores é defendida por vários autores que apoiam sua contribuição na competência profissional, sendo os principais Ozar (1993) e Eraut et al. (1994).

As

(metaqualidades ou meta-habilidades) podem ampliar e reforçar outras competências ou podem ser importantes para a sua aquisição. São exemplos: a capacidade analítica, a criatividade e a habilidade de aprendizagem equilibrada (aprender a aprender). Da mesma maneira, as transcompetências perpassam outras 
competências por serem genéricas e comuns, tais como a comunicação e a agilidade mental. As transcompetências correspondem a um tipo de competência que se integra a outras, mediando sua expressão, podendo ser determinantes no seu desenvolvimento ou aprendizagem.

A dinâmica do modelo, a partir da identificação das metacompetências, juntamente com os quatro componentes centrais (competência de conhecimento ou cognitiva; competência funcional; competência pessoal ou comportamental e competência de valores/ética) e seus subcomponentes, interage para produzir uma gama de resultados: macrorresultados (os resultados abrangentes e globais da atividade profissional); microrresultados (os resultados de atividades mais específicas); e resultados parciais (os resultados de uma atividade parcialmente concluída).

Embora o modelo de competências profissionais proposto por Cheetham e Chivers (1998) não tenha sido desenvolvido especificamente para as competências gerenciais, tal modelo será usado como um dos norteadores na identificação das competências desenvolvidas pelos gerentes das instituições financeiras pública $\mathrm{e}$ privada por meio da utilização de determinadas estratégias de aprendizagem, que também serão identificadas no presente estudo.

\section{METODOLOGIA}

\subsection{Coleta de Dados}

Nesta pesquisa, os principais dados foram obtidos por meio de entrevistas, entretanto o uso da observação informal não estruturada (pesquisador atuando como mero expectador) das empresas pesquisadas e a consulta de documentos, como por exemplo o site das empresas e os relatórios obtidos em instituições de apoio ao setor bancário, contribuíram para o processo de análise dos dados.
Um roteiro de perguntas com linhasmestras ou guias de tópicos foi construído para um direcionamento na elaboração das perguntas (GODOY, 2006). Esse roteiro foi elaborado a partir das teorias estudadas e da observação de pesquisas anteriores com objetivos semelhantes. As entrevistas foram registradas pelos pesquisadores por meio de gravação direta com autorização dos entrevistados. Godoy (2006) afirma que esse recurso permite que todas as expressões orais sejam arquivadas, existindo a possibilidade de examiná-las novamente, se necessário.

\subsubsection{Contexto}

$\mathrm{O}$ artigo contempla como área de estudo instituições financeiras. Embora seja visto como um mercado tradicional e burocrático no Brasil, o setor bancário vem passando por profundas transformações nos últimos anos, principalmente devido ao surgimento e à expansão das chamadas Fintechs, termo que surge a partir de uma combinação entre as palavras em inglês financial (finanças) e technology (tecnologia) (SILVA et al., 2020). Em razão dessas mudanças tecnológicas, os profissionais do setor bancário tiveram que adquirir novas competências técnicas e comportamentais para o desempenho de suas atividades diárias. Uma das formas para acompanhar todo o processo de evolução desse setor da economia é fazer uso de estratégias de aprendizagem informal no trabalho, o que pode favorecer a observação dos fenômenos estudados neste artigo.

O banco público participante desta pesquisa é uma instituição financeira $100 \%$ pública. A empresa exerce um papel relevante na promoção do desenvolvimento urbano e da justiça social do país, uma vez que prioriza setores como habitação, saneamento básico, infraestrutura e prestação de serviços, contribuindo para melhorar a vida das pessoas, principalmente as de baixa renda. Além disso, essa instituição financeira pública apoia 
inúmeras atividades artísticas, culturais, educacionais e desportivas (FORTUNA, 2005). Por outro lado, o banco privado participante desta pesquisa é uma instituição financeira privada brasileira, porém com atuação em outros países. O banco figura na lista dos dez maiores bancos do mundo, contando com mais de 100 mil empregados no Brasil e em outros países, mais de 4000 agências brasileiras de serviços, 900 postos de atendimento bancário e mais de 28 mil caixas eletrônicos espalhados pelo país.

As contratações para o ingresso em uma instituição financeira pública acontecem por meio de concursos públicos, que são lançados em editais publicados no Diário Oficial da União. Via de regra, os concursos públicos para a área bancária exigem formação de nível médio e, dependendo do cargo, qualificação de nível superior também pode ser requerida. Os candidatos aprovados passam a gozar de relativa estabilidade no exercício da profissão, embora sejam submetidos à Consolidação das Leis Trabalhistas, cuja relação possui cunho contratual, além de serem submetidos a avaliações de desempenho. Já, para ser contratado por uma instituição financeira privada, é necessário estar cursando ou ter concluído um curso de nível superior. Certificações na área financeira podem representar um diferencial para os candidatos postulantes a uma vaga. Diferentemente das instituições financeiras públicas, os bancos privados disponibilizam vagas de emprego em suas respectivas páginas da Internet ou em sites especializados em recolocação profissional, que recebem e/ou armazenam os currículos dos candidatos. Os selecionados ainda fazem testes on-line ou presenciais, dinâmicas de grupo ou entrevistas presenciais. Os candidatos aprovados não gozam de estabilidade no exercício da profissão e são submetidos a constantes avaliações de desempenho como forma de medir suas competências técnicas e comportamentais. Essas discrepâncias entre bancos públicos e privados podem sugerir diferenças em relação à utilização de estratégias de aprendizagem informal para o desenvolvimento de competências, uma vez que o perfil profissional requerido para bancos públicos e privados se mostra distinto.

A escolha por Gerentes de Pessoa Física e de Pessoa Jurídica se deu porque os mesmos têm atribuições funcionais muito semelhantes, o que possibilita comparações. Os critérios para participação dos gerentes na presente pesquisa foram os seguintes: pertencer a um dos dois bancos estabelecidos previamente pelos pesquisadores; ocupar o cargo de "Gerente de Pessoa Física e/ou Jurídica" e atuar nesse cargo há, pelo menos, um ano; e trabalhar na cidade de São Paulo. Os gerentes participantes da pesquisa não precisam trabalhar, necessariamente, na mesma agência das instituições financeiras pesquisadas. $\mathrm{O}$ contato com os gerentes participantes da pesquisa ocorreu pela indicação de pessoas do grupo social e profissional dos pesquisadores. A Tabela 2 apresenta o perfil dos dez gerentes que foram entrevistados neste estudo:

Tabela 2 - Perfil demográfico dos participantes da pesquisa

\begin{tabular}{cccccc} 
Entrevistado & Gênero & Idade & Gerente de... & $\begin{array}{c}\text { Tempo } \\
\text { Empresa } \\
\text { (gerente) }\end{array}$ & Graduação (Pós) - Completos \\
\hline Pública_1 & F & 48 & Pessoa jurídica & $26(15)$ & Administração (Gestão Financeira) \\
\hline Pública_2 & M & 49 & Pessoa jurídica & $17(8)$ & Engenharia Agronômica \\
\hline Pública_3 & M & 41 & Pessoa jurídica & $17(2)$ & Administração (Controladoria) \\
\hline Pública_4 & F & 38 & $\begin{array}{c}\text { Pessoa física e } \\
\text { jurídica }\end{array}$ & $17(5)$ & Pedagogia (Docência Ensino Superior)
\end{tabular}




\begin{tabular}{cccccl} 
Pública_5 & F & 32 & $\begin{array}{c}\text { Pessoa física e } \\
\text { jurídica }\end{array}$ & $13(1)$ & Administração (Língua Inglesa) \\
\hline Privada_1 & M & 38 & Pessoa física & $5(5)$ & Administração (Gestão de Pessoas) \\
\hline Privada_2 & M & 29 & Pessoa física & $8(1)$ & Recursos Humanos \\
\hline Privada_3 & F & 37 & Pessoa física & $1(1)$ & Administração de Empresas \\
\hline Privada_4 & F & 29 & Pessoa física & $1(1)$ & Administração de Empresas \\
\hline Privada_5 & M & 31 & $\begin{array}{c}\text { Pessoa física e } \\
\text { jurídica }\end{array}$ & $11(5)$ & Publicidade e Propaganda
\end{tabular}

Legenda: $\mathrm{M}=$ masculino, $\mathrm{F}=$ feminino. Idade e tempo de empresa (gerente) em anos.

Fonte: Resultados da pesquisa

Nota: O princípio de "saturação" ou de "redundância" (GODOI; MATTOS, 2006) foi utilizado nesta pesquisa para determinação do número de entrevistas realizadas.

\subsection{Análise dos Dados}

Neste estudo, os dados obtidos nas entrevistas foram analisados por meio da técnica de templates, de King (2004). O termo "análise de template" não se refere apenas a um método único e claramente delineado, porém se trata de um grupo de técnicas para tematicamente organizar e analisar dados textuais. A essência da análise de template é que o pesquisador produz uma lista de códigos (templates) representando temas identificados nos seus dados textuais. Os templates são organizados de um modo que representam as relações entre os temas, assim definidos pelo pesquisador, envolvendo uma estrutura hierárquica (KING, 2004).

Segundo King (2004), o melhor ponto de partida para a construção de um template inicial são os guias de tópicos do roteiro para a entrevista. As principais questões do roteiro para a entrevista podem servir como códigos de ordem superior, e questões subsidiárias como códigos potenciais de ordem inferior.

\section{RESULTADOS}

\subsection{As Estratégias de Aprendizagem Informal dos Gestores}

Para que os objetivos propostos neste estudo possam ser alcançados, procurou-se identificar nas entrevistas com os participantes da pesquisa as diferentes estratégias de aprendizagem utilizadas por gestores no desenvolvimento de competências, segundo Antonello (2011), por se tratar da literatura mais atual neste campo do conhecimento.

\subsubsection{Banco Público}

Conforme as transcrições a seguir, é possível afirmar que os gerentes entrevistados na instituição financeira pública (Pública_1 e Pública_3) utilizam a estratégia de aprendizagem informal no trabalho experiência anterior e transferência extraprofissional:

[...] Procuro fazer as tarefas do dia a dia com base nas minhas experiências anteriores que tive aqui no banco, afinal de contas, são 25 anos de experiência. Comecei aqui como todo mundo, como técnico bancário e fui encarreirando no banco ao longo dos anos. Acho que toda essa experiência é fundamental pro meu cargo atual [...] (Pública 1)

[...] No departamento que eu tô agora, pra você ser gerente, você precisa ler o trabalho do relatório que o assistente sênior, o assistente pleno ou o assistente júnior faz, então você tem que saber o que que ele tá fazendo lá, né, o conhecimento técnico da coisa. Tem gente que consegue ser gerente sem passar por esses graus, mas eu, minha opinião é contrária a isso, eu não sou a favor disso, não. Eu acho que a pessoa tem que ter a mão na massa lá, de saber o operacional antes de virar gerente [...] (Pública_3) 
A gerente Pública_1 ressalta a importância de sua vasta experiência na instituição financeira para o desempenho de suas tarefas diárias. $\mathrm{O}$ entrevistado Pública_3, por sua vez, destaca a necessidade de o profissional assumir funções mais operacionais antes de ser promovido ao cargo gerencial, a fim de conhecer as atividades executadas, hoje, por seus assistentes. Aqui, a estratégia de aprendizagem experiência anterior está intimamente ligada à estratégia de aprendizagem observaçãomodelo/reprodução, ainda a ser apresentada e analisada nesta subseção.

As estratégias de aprendizagem interação e colaboração/busca por ajuda interpessoal e consulta a material escrito foram citadas várias vezes pelos gerentes da instituição financeira pública.

A gerente Pública_1 demonstra recorrer à estratégia de aprendizagem consulta a material escrito, pois, segundo ela, é uma maneira de se manter atualizada sobre os informes do banco:

[...] Procuro fazer as coisas com base nas minhas experiências anteriores que tive aqui no banco, afinal de contas, são mais de 25 anos de experiência... Há também muita coisa pra ler: informativos, normas, leis novas... tenho que ler tudo pra me manter atualizada. (Pública_1)

Já, o gerente Pública_2 utiliza a estratégia de aprendizagem interação e colaboração/busca por ajuda interpessoal.

[...] Basicamente, eu procuro ajuda de outros gerentes da mesma área, de colegas de trabalho com o mesmo nível hierárquico. Aqui, na agência, temos um "mensageiro", que serve pra gente trocar mensagens em tempo real com qualquer funcionário do banco. Assim que eu preciso de uma informação mais detalhada, eu procuro me comunicar (por meio de um mensageiro) com outros gerentes que já tenham resolvido problemas similares. Às vezes, essa comunicação entre gerentes de mesma função é feita por telefone ou e-mail [...] (Pública 2)
Pode-se verificar que os participantes reconhecem a importância do material escrito (normativos e instruções editados pela organização), porém, devido às pressões do ambiente profissional e à falta de tempo para uma leitura adequada nas agências bancárias investigadas, a maior parte deles, então, procura ajuda interpessoal/interação e colaboração, por meio de o auxílio de colegas de trabalho com o mesmo nível hierárquico.

\subsubsection{Banco Privado}

Uma das estratégias de aprendizagem observadas nas falas dos gerentes participantes Privada_1 e Privada_4 é a observaçãomodelo/reprodução.

O gerente Privada_1 afirma que utiliza a estratégia de aprendizagem reprodução; em um primeiro momento, observando o comportamento de colegas de trabalho com mais experiência no exercício do cargo gerencial; em seguida, colocando em prática aquilo que, previamente, fora examinado:

Já fiz e, normalmente, faço também (aprender por reprodução). Eu, dependendo da informação, é claro, se eu verificar que é algo... também... tá muito diferente do que eu acredito do que seja a forma correta, eu vou buscar outras informações, ou na própria Intranet, mas, basicamente, dentre as pessoas que eu busco as informações, que são pessoas um pouco mais experientes, ou até mesmo já com uma larga experiência da função que tá sendo exercida, eu observo, primeiro, e faço de acordo com o que ela me passou também, meio que já reproduzo. (Privada_1)

É interessante observar na transcrição a seguir a distinção que a gerente Privada_4 faz em relação à estratégia de aprendizagem observaçãomodelo/reprodução: ela afirma não utilizar tal estratégia quando tem como referência seus colegas de trabalho, por acreditar que 
cada cliente demanda um atendimento personalizado, ou seja, o cliente é quem molda o comportamento do seu gerente; entretanto, a gerente em questão admite utilizar a estratégia de aprendizagem observação-modelo/reprodução tendo como base seus superiores hierárquicos (modelos de liderança a serem seguidos), uma vez que almeja um cargo gerencial de maior importância na estrutura hierárquica do banco pesquisado:

Olha, eu já tentei fazer isso (aprender por reprodução), mas não consigo porque acho que cada um desenvolve um jeito, então, por mais que funcione pra aquela pessoa, talvez pra mim não funcione, porque, muitas vezes, a colocação, o cliente, porque a gente sente o cliente, né, então a gente tá sentindo o cliente pra gente poder oferecer alguma coisa ou apresentar alguma solução, então eu acho que cada caso vai ser diferente... Então, já tentei porque ah, deu certo, puxa, esse mês a pessoa conseguiu, eu não tô conseguindo, vou fazer igual, não funciona, eu tenho que identificar uma forma minha própria pra eu conseguir atingir aquele objetivo... Espelhar a gente se espelha em cargo... que nem, eu busco um cargo de liderança maior, então eu busco os líderes em destaque, então são pessoas que eu olho [...] (Privada_4)

Em relação às estratégias de aprendizagem interação

\section{e} colaboração/busca por ajuda interpessoal e consulta a material escrito, é possível observá-las nas transcrições a seguir:

Num primeiro momento, eu vou buscar os meus pares que, porventura, possam ter alguma informação já mais recente, ou até mesmo maior experiência pra poderem me auxiliar. É mais rápido, mais fácil. A busca... eu sempre vou no meu par. (Privada_1)

Tá, vamos lá, além de consultar pares, lógico que ajuda muito, cada um tem sua experiência de vida e profissional também, a gente recebe e-mail de atualização, de produtos... Nessas informações são atualização de produtos, recomendações, como tá o mercado, painel econômico e, além disso, a gente tem todo um material de apoio pra qualquer informação que a gente possa passar pro cliente, seja de produto, de investimento, de conquista, a gente tem um material nosso de apoio, como se fosse uma Intranet mesmo, tá, nesse material de apoio a gente tem um leque de opções que a gente consegue consultar tudo que precisa dentro de todos os produtos do banco... O par, a gente consulta mais por experiência, né... A gente tem, troca bastante essa conversa dentro da agência praticamente o dia inteiro [...] (Privada 2)

Analisando as falas dos gerentes participantes da instituição financeira privada referentes às estratégias de aprendizagem interação e colaboração/busca por ajuda interpessoal e consulta a material escrito, é possível afirmar que, assim como verificado nas falas dos gerentes participantes do banco público, há uma preferência natural pela utilização da estratégia de aprendizagem interação e busca por ajuda interpessoal, uma vez que recorrer a pares ou a superiores hierárquicos, quando se tem a necessidade de informações mais detalhadas para a execução do trabalho, é mais prático e rápido, principalmente em um ambiente de trabalho onde há falta de tempo para uma leitura adequada de normativos e manuais editados pela organização devido às pressões e demandas do dia a dia.

Vale destacar que os gerentes pertencentes à instituição financeira privada pesquisada, diferentemente dos gerentes pertencentes ao banco público pesquisado, dispõem de uma central de atendimento ao gerente, ou seja, um número telefônico de atendimento para gerentes sempre que houver a necessidade de uma orientação sobre algum produto/serviço ou procedimento do banco. Além disso, é possível afirmar, com base nas falas dos participantes, que os gerentes do banco privado contam com um sistema de busca 
semelhante ao Google, no qual os usuários podem pesquisar informações relativas ao universo financeiro, facilitando, dessa forma, a aprendizagem e o desenvolvimento de competências gerenciais.

\subsubsection{Banco Público Versus Banco Privado: comparação das estratégias de aprendizagem}

A Tabela 3 apresenta as estratégias de aprendizagem no trabalho comuns e particulares utilizadas pelos gerentes das instituições financeiras pública e privada.

Conforme é possível observar na aprendizagem definidas por Antonello (2011), não há, de maneira geral, diferenças significativas na utilização dessas estratégias pelos gerentes entrevistados das instituições financeiras pública e privada.

Considerando-se as especificidades (diferenças) entre os bancos público e privado, por um lado, a estratégia de aprendizagem experienciar não é observada nas falas dos gerentes oriundos da instituição financeira pública, pois nenhum deles vivenciou tais situações ao longo de suas carreiras profissionais.

Tabela 3, e, de acordo com as estratégias de

Tabela 3 - Comparação das estratégias de aprendizagem entre banco público e banco privado

\begin{tabular}{|l|l|}
\hline Comparação & \multicolumn{1}{|c|}{ Estratégias de Aprendizagem } \\
\hline \multirow{4}{*}{ Comunalidades } & Experiência anterior e transferência extraprofissional \\
\cline { 2 - 3 } & Reflexão Extrínseca e Intrínseca \\
\cline { 2 - 3 } & Autoanálise \\
\cline { 2 - 3 } & Observação-modelo/reprodução \\
\cline { 2 - 3 } & Mudança de perspectiva \\
\cline { 2 - 3 } & Interação e colaboração/busca por ajuda interpessoal \\
\cline { 2 - 3 } & Consulta a material escrito \\
\cline { 2 - 3 } & Cursos e treinamentos \\
\cline { 2 - 3 } & Aprendizagem pela articulação entre teoria e prática \\
\hline \multirow{2}{*}{ Especificidades } & Experienciar - observada apenas no banco privado \\
\cline { 2 - 3 } & Mentoria (mentoring) e tutoria (coaching) - observada apenas no banco público \\
\hline
\end{tabular}

Fonte: Elaborado pelo autor com base nas entrevistas.

Por outro lado, na instituição financeira privada, a estratégia de aprendizagem experienciar é revelada na fala de um dos gerentes participantes desta pesquisa (Privada_5), uma vez que o banco onde ele trabalhava fora adquirido por outro banco privado, em um processo de fusão, possibilitando ao gerente em questão aprender por meio de experiências advindas de situações difíceis e processos de mudança organizacional.

Outra especificidade entre os bancos público e privado, é a estratégia de aprendizagem mentoria e tutoria, que é ser assistido por um mentor ou tutor no processo de desenvolvimento de competências gerenciais (ANTONELLO, 2011). É possível observá-la na fala de uma das gerentes pertencentes à instituição financeira pública (Pública_4). Segundo essa gerente, o banco já tentou institucionalizar tal prática de aprendizagem informal, porém sem muito sucesso.

A estratégia de aprendizagem observação-modelo/reprodução, que é a observação estruturada e crítica dos outros, de acordo com Antonello (2011), pôde favorecer o surgimento da estratégia de aprendizagem mentoria e tutoria na instituição financeira pública. Em relação ao banco privado, a estratégia de 
aprendizagem mentoria e tutoria não é observada nas falas de nenhum dos gerentes entrevistados.

\subsection{Desenvolvimento de Competências Gerenciais}

A fim de atingir os objetivos propostos neste trabalho, procurou-se, também, identificar nas entrevistas com os participantes da pesquisa as diferentes competências gerenciais, segundo o modelo de Cheetham e Chivers (1996, 1998, 2005), por ser metodologicamente útil para a finalidade do presente estudo.

\subsubsection{Banco Público}

As competências cognitivas ou de conhecimento são apresentadas e analisadas, conforme as transcrições selecionadas a seguir.

A gerente Pública 1 sustenta que, para ser gerente da instituição financeira pesquisada, é obrigatório ter graduação, preferencialmente em cursos como Administração de Empresas, Economia, Ciências Contábeis ou Direito. Um curso de pós-graduação pode ser considerado como um diferencial no processo de recrutamento interno que seleciona gerentes para o banco. Segundo a entrevistada, uma formação acadêmica consistente contribui para uma melhor compreensão das atividades de um gerente:

[...] É obrigatório ter um curso superior, pode ser em qualquer área, de preferência, em áreas relacionadas, por exemplo, Administração, Economia, Contabilidade, Direito. Um curso de pós-graduação também é muito importante, pode ser um diferencial pra você ser promovido. Eu sou formada em Administração e tenho uma pós em Gestão Financeira, que me ajudou muito a entender todo o meu trabalho [...] (Pública_1)

Já, o gerente Pública_2 atenta para o fato de que há uma certificação obrigatória para que um profissional atue como gerente bancário: a CPA-10. Essa certificação é destinada a profissionais que atuam na prospecção ou venda de produtos de investimento (títulos, valores mobiliários, incluindo os derivativos, disponíveis no mercado financeiro e de capitais brasileiro) junto ao público investidor, inclusive em agências bancárias ou plataformas de atendimento (meio eletrônico e telefônico) (ANBIMA, 2016):

[...] Pra você ser gerente de contas, você precisa de uma certificação chamada CPA-10, que é obrigatória agora. Sem essa certificação você não consegue mais trabalhar como gerente em agência... É uma certificação que te habilita a trabalhar com produtos financeiros [...] (Pública_2)

Tomando como base aqui a definição de competências advinda da corrente norte-americana, representada principalmente por McClelland e Dailey (1972) e Boyatzis (1982), e a definição e classificação de Cheetham e Chivers (1996, 1998, 2005), as competências cognitivas ou de conhecimento podem ser analisadas sob dois aspectos.

Primeiro, se considerarmos que as competências cognitivas ou de conhecimento referem-se aos conhecimentos fundamentais para que uma determinada profissão possa ser exercida, então sua aquisição pode acontecer por meio da aprendizagem formal, baseada em sala de aula e altamente estruturada (MARSICK; WATKINS, 2001). Para os gerentes pertencentes à instituição financeira pública, por exemplo, ter graduação completa é requisito fundamental para o exercício do cargo gerencial, portanto, nesse caso, a aprendizagem formal prevalece sobre a informal.

Segundo, se levarmos em conta que as competências cognitivas ou de conhecimento são divididas, segundo Cheetham e Chivers (1996, 1998, 2005), em conhecimento tácito-prático, conhecimento procedimental e conhecimento contextual, pode-se afirmar que a aquisição de tais 
competências se dá por meio da aprendizagem informal.

Quando as competências cognitivas ou de conhecimento são analisadas com base no segundo aspecto, e por se tratarem de conhecimentos fundamentais ao exercício de uma profissão, toda e qualquer estratégia de aprendizagem definida por Antonello (2011) pode ser um meio para adquirir, armazenar ou recuperar essas informações básicas.

As competências funcionais são aquelas relacionadas às múltiplas tarefas de uma profissão particular. É possível observar, com base nas falas dos participantes Pública_2, Pública_3 e Pública_4, as habilidades de planejamento, delegação e acompanhamento ou avaliação das diferentes tarefas inerentes ao cargo gerencial exemplificadas a seguir:

[...] Eu preciso planejar as atividades diárias, semanais, mensais... tem coisas que são mais urgentes que outras, por exemplo, é preciso ter essa noção. É importante saber delegar tarefas quando a carga de trabalho aumenta, daí a importância da sua equipe, dos assistentes... e não é só delegar, tem que fazer um follow-up (acompanhamento) de tudo isso [...] (Pública_2)

O gerente Pública_3 reconhece que ainda precisa aprimorar a capacidade de saber delegar tarefas. Segundo o entrevistado, essa competência é vital para a carreira gerencial:

[...] Eu sou uma pessoa muito centralizadora por natureza e, se você fica voltado só pro seu eu, você não sobrevive como gerente, né, você tem que tá sempre delegando pra todos, né, da sua equipe... Estou desenvolvendo essa competência agora [...] (Pública_3)

As competências funcionais podem ser facilmente identificadas na fala da gerente Pública_4. A profissional, sabendo que detém um número reduzido de assistentes para ajudá-la na execução das tarefas, precisa sempre pensar sobre formas alternativas para cumprir as exigências impostas pelo cargo gerencial e, consequentemente, atingir seus resultados:

[...] Na minha atribuição, eu tenho que pensar o tempo todo... Eu tenho um recurso limitado, meu recurso humano pra fazer o universo de coisas que eu tenho pra fazer é limitado em comparação ao resultado que eu preciso chegar, né, então, eu tenho que o tempo todo estar pensando nisso, como eu vou fazer mais com menos, né, dentro da rotina operacional interna [...] (Pública_4)

As competências funcionais podem ser adquiridas por meio de determinadas estratégias de aprendizagem, como por exemplo a reflexão. Quando uma situaçãoproblema emerge, os gerentes procuram identificar maneiras para solucioná-la.

Outra estratégia de aprendizagem que contribui para a obtenção de competências funcionais é a autoanálise. Sabendo avaliar características pessoais, os gerentes conseguem identificar habilidades que ainda precisam ser aprimoradas para atender às múltiplas tarefas que o cargo gerencial exige, alcançando, dessa maneira, as competências funcionais.

\subsubsection{Banco Privado}

No que tange às competências pessoais ou comportamentais, vale notar as falas dos participantes Privada_1 e Privada_4, de acordo com as transcrições a seguir.

Com base na fala do gerente Privada_1, observa-se que o subcomponente intraprofissional, aquele ligado aos comportamentos referentes à interação com outros profissionais ou clientes, de acordo com Cheetham e Chivers (1996, 1998, 2005), é uma competência pessoal ou comportamental aqui identificada e que, segundo o entrevistado, o gerente precisa ter desenvoltura, principalmente em situações 
críticas com seus clientes, para a resolução de problemas:

[...] Essa questão de relacionamento com o cliente, ter esse jogo de cintura, né, na parte comercial, exige bastante porque, ao mesmo tempo que surgem situações adversas com o cliente, você precisa ter um jogo de cintura pra poder lidar com aquela situação [...] (Privada_1)

A gerente Privada_4 cita o equilíbrio emocional, a paciência e a segurança ao falar como capacidades pessoais ou comportamentais que ela teve de desenvolver como gerente:

[...] Aprendi muito a entender, né, assim, o cliente, se colocar no lugar do cliente também, ter um equilíbrio porque, no começo, a gente quer tanto, tanto aquilo e a gente se dedica, se dedica e a gente acaba perdendo a outra ponta, a família, amigos, então, aprendi a ter equilíbrio emocional, muita paciência, nossa, como tive que desenvolver a paciência... e segurança, né, desenvolvi muito a segurança porque, quando você fala, você tá falando de um patrimônio de uma outra pessoa, então você tem que fazer com que essa pessoa se sinta segura em seguir suas recomendações, então eu tenho que me aprofundar, eu preciso estudar, me atualizar pra passar segurança pros meus clientes também. (Privada_4)

Para a competência de valores ou de ética, a única fala que cita tal capacidade entre os entrevistados da instituição financeira privada é a do gerente Privada_1.

Para o gerente Privada_1, a transparência é um valor a ser considerado na relação que se estabelece entre gerente e cliente. Segundo Cheetham e Chivers (1996, 1998, 2005), o subcomponente profissional do componente competência de valores ou de ética trata, também, sobre a atenção aos direitos dos clientes, e é aqui enfatizado pelo entrevistado:

[...] Eu, particularmente, eu prezo muito a ética, né, muito a transparência, então, eu procuro ser muito transparente com o cliente, quando realmente dá pra fazer algo, eu vou me empenhar, me colocar à disposição, quando não der, simplesmente vou falar: "olha, realmente, nós fizemos o possível, mas, infelizmente, eu tenho que me reportar à hierarquia, a um departamento, e a decisão, muitas vezes, vem de cima e a gente não tem autonomia nesse sentido". Então, eu procuro ser transparente. (Privada_1)

É importante considerar que os gerentes entrevistados não conseguem identificar quais estratégias de aprendizagem são utilizadas, de fato, para adquirir ou aprimorar cada competência, e que a competência não é desenvolvida em apenas um momento ou evento.

\section{DISCUSSÃO DOS RESULTADOS}

O presente estudo buscou identificar as estratégias de aprendizagem informal no trabalho utilizadas por gerentes no desenvolvimento de suas competências em instituições financeiras pública e privada.

Os resultados indicam que a grande maioria dos gerentes participantes desta pesquisa ( 8 de 10) construiu a carreira profissional dentro de instituições financeiras. A experiência gerencial, por exemplo, foi adquirida e exercida somente em bancos.

Em relação às estratégias de aprendizagem, tanto para os gerentes entrevistados pertencentes à instituição financeira pública quanto para os gerentes entrevistados oriundos do banco privado, houve uma preferência natural pela utilização da estratégia de aprendizagem interação e colaboração/busca por ajuda interpessoal, uma vez que recorrer a pares ou a superiores hierárquicos, quando se tem a necessidade de informações mais detalhadas para a execução do trabalho, é mais prático e rápido, principalmente em um ambiente de trabalho onde há falta de tempo para uma leitura adequada de normativos e manuais editados pela organização devido às pressões e demandas do dia a dia. 
Considerando-se as especificidades entre os bancos público e privado, a estratégia de aprendizagem experienciar não foi observada nas falas dos gerentes oriundos da instituição financeira pública. $\mathrm{Na}$ instituição financeira privada, a estratégia de aprendizagem experienciar foi revelada na fala de um dos gerentes participantes desta pesquisa (Privada_5). Outra especificidade entre os bancos público e privado, é a estratégia de aprendizagem mentoria e tutoria, que foi observada na fala de um dos gerentes pertencentes à instituição financeira pública (Pública_4). Em relação ao banco privado, a estratégia de aprendizagem mentoria e tutoria não foi observada nas falas de nenhum dos gerentes entrevistados.

Já, em relação ao desenvolvimento de competências gerenciais, quando as razões que levaram o participante a ser indicado para exercer a função gerencial foram analisadas, foi possível notar que, assim como acontece na instituição financeira pública, no banco privado os candidatos a um cargo gerencial precisam passar por um recrutamento interno formal e atender a determinadas exigências para serem promovidos. A diferença em relação à instituição financeira pública é que, no banco privado, os gerentes entrevistados não questionam os critérios de seleção, pois não creditam a escolha feita pela organização a fatores políticos ou de influência pessoal.

A maioria dos gerentes entrevistados (8 de 10) admite que as competências pessoais ou comportamentais são aquelas que ainda precisam de mais aprimoramento, quando comparadas com as demais competências profissionais.

\section{CONSIDERAÇÕES FINAIS}

Tomando como referência este trabalho, uma implicação prática pode resultar na elaboração de uma proposta para a implantação de um Programa de Aprendizagem Gerencial (processo que envolve atividades de aprendizagem formal e ações de desenvolvimento focadas na ação), com o objetivo de fomentar o conhecimento de teorias, métodos e técnicas para o desenvolvimento e a operacionalização dos processos gerenciais, além de favorecer o desenvolvimento da visão sistêmica e a reflexão sobre as atitudes, os comportamentos no contexto gerencial e também o autoconhecimento.

Hoje, fala-se muito que o indivíduo é o responsável pelo próprio desenvolvimento, mas a organização também tem sua parcela de responsabilidade, uma vez que não se aprende apenas em um curso de formação ou aperfeiçoamento profissional, mas também na prática gerencial - e isso indica que a empresa deve criar um ambiente propício para que as pessoas aprendam (SILVA, 2009).

Já, para a academia, uma implicação teórica pode ser o caráter complementar deste estudo. No Brasil, já foram realizadas algumas pesquisas, principalmente quantitativas, sobre a intensidade de uso e a sequência de uso das estratégias de aprendizagem informal, em funções como: operários da indústria automotiva (USHIRO; BIDO, 2016); enfermeiros e técnicos em enfermagem (CONTE; BIDO; GODOY, 2011); Pantoja e Borges-Andrade (2009) estudaram dezesseis ocupações profissionais (programador, pesquisador, frentista de posto de gasolina, garçom etc.); e Hito (2011) estudou a função da aprendizagem gerencial em bancos, para citar alguns trabalhos.

Dessa forma, a presente pesquisa complementa as anteriores (por exemplo: Closs e Antonello (2014)) porque busca um entendimento mais profundo destas estratégias ao analisá-las de modo qualitativo, além de ter um enfoque no nível gerencial e relacionar as estratégias de aprendizagem no trabalho identificadas por Antonello (2011) com o modelo de competências proposto por Cheetham e Chivers (1996, 1998, 2005). 
Por fim, é importante enfatizar que a aprendizagem ocorre de várias maneiras e em diferentes níveis, mas sempre de forma complexa (STACEY, 1998 apud SILVA, 2009). À medida que um gerente desempenha sua função e sistematiza suas práticas na organização, não limita seu aprendizado à aquisição de competências, mas aprende a pensar, a sentir e a se avaliar como gerente (HILL, 1993 apud SILVA, 2009). Uma competência é adquirida ou potencializada quando o gerente amplia as suas experiências, à medida que aumenta a sua vivência de situações profisssionais, utilizando não só os conhecimentos adquiridos na sua formação educacional, mas também as experiências vividas no trabalho e na vida pessoal (SILVA, 2009).

Por ser um estudo qualitativo, a generalização dos resultados fica impossibilitada, pois não há margem de segurança estatística em relação às inferências obtidas. É importante lembrar que o método qualitativo não tem a intenção de garantir a validade externa (GODOY, 2006).

Como a coleta de dados se baseou em entrevistas, algumas limitações podem ser mencionadas sobre este aspecto: os resultados estão limitados àquilo que os entrevistados conseguiram lembrar no decorrer das entrevistas; e aquilo que os gerentes entrevistados lembraram pode ser diferente daquilo que realmente aconteceu na época do evento relatado, por motivo de esquecimento ou pelo fato de o relato ser mais uma interpretação deles sobre o que aconteceu do que realmente uma "fotografia" dos acontecimentos.

Sugere-se uma pesquisa quantitativa para complementar este estudo, buscando possível generalização para outros contextos. Além disso, recomenda-se que, em pesquisas futuras, sejam contemplados gerentes de outras áreas profissionais e/ou de diferentes segmentos de atividade da organização.

Os objetivos propostos para o presente trabalho foram atingidos, enquanto pesquisa qualitativa interpretativa básica, com base em Godoy (2006). Espera-se que os resultados apresentados possam contribuir, de alguma forma, para um maior embasamento conceitual da área temática, seja pela utilização de uma abordagem inovadora, ou ainda, pela questão da complementaridade de estudos realizados nessa área.

\section{REFERÊNCIAS}

ANBIMA. Associação Brasileira das Entidades dos Mercados Financeiro e de Capitais. Disponível em: http://certificacao.anbid.com.br/cpa10.asp. Acesso em 21 ago. 2016.

ANTONELLO, C. S. Saberes no singular? A falsa fronteira entre aprendizagem formal e informal. In: ANTONELLO, C. S.; GODOY, A. S. (Orgs.) Aprendizagem organizacional no Brasil. Porto Alegre: Bookman, 2011, p. 225-245.

BRANDÃO, H. P.; BORGES-ANDRADE, J. E. Causas e efeitos da expressão de competências no trabalho: Para entender melhor a noção de competência. Revista de Administração Mackenzie, v. 8, n. 3, p. 32-49, 2007.

BOYATZIS, R. E. The competent manager. New York: Wiley, 1982.

CHEETHAM, G.; CHIVERS, G. Towards a holistic model of professional competence. Journal of European Industrial Training, Bradford, v. 20, n. 5, p. 20-30, 1996.

CHEETHAM, G.; CHIVERS, G. The reflective (and competent) practitioner. A model of professional competence which seeks to harmonise the reflective practitioner and competence-based approaches. Journal of European Industrial Training, Bradford, v. 22, n. 7, p. 267-276, 1998. 
CHEETHAM, G.; CHIVERS, G. Professions, competence and informal learning. Cheltenham, UK: Edward Elgar, 2005 .

CLOSS, L.; ANTONELLO, C. S. Aprendizagem de gestores no contexto das transformações contemporâneas no mundo do trabalho. RCA - Revista de Ciências da Administração, v.16, n.39, p.146-163, 2014.

CONTE, D. L.; BIDO, D. S.; GODOY, A. S. Estratégias de Aprendizagem Informal de Enfermeiros. In: ENCONTRO DA ASSOCIAÇÃO NACIONAL DE PÓSGRADUAÇÃO E PESQUISA EM ADMINISTRAÇÃO - ENANPAD, 35, 2011, Rio de Janeiro. Anais [...]. Rio de Janeiro: ANPAD, 2011.

DURAND, T. L'alchimie de la competénce. Revue Française de Gestion, v. 127, n. 1, p. 84-102, 2000.

ERAUT, M.; STEADMAN, S.; COLE, G.; MARQUAND, J. Ethics in occupational standards, NVQs and SVQs. Sheffield: Employment Department, 1994.

FORTUNA, E. Mercado Financeiro: Produtos e Serviços. 16. ed. Rio de Janeiro: Qualitymark, 2005.

FREITAS, I. A.; BRANDÃO, H. P. Trilhas de aprendizagem como estratégia de TD\&E. In: BORGES-ANDRADE, J. E.; ABBAD, G.; MOURÃO, L. (Orgs.). Treinamento, desenvolvimento e educação em organizações e trabalho: Fundamentos para a gestão de pessoas. Porto Alegre: Artmed-Bookman, 2006, p. 97-113.

GODOI, C. K.; MATTOS, P. L. C. L. Entrevista qualitativa: Instrumento de pesquisa e evento dialógico. In: GODOI, C. K.; BANDEIRA-DE-MELLO, R.; SILVA, A. B.; (Orgs.). Pesquisa Qualitativa em Estudos Organizacionais: Paradigmas,
Estratégias e Métodos. São Paulo: Ed. Saraiva, 2006, p. 308-310.

GODOY, A. S. Estudo de Caso Qualitativo. In: GODOI, C. K.; SILVA, A. B.; BALSINI, C. P. V. (Orgs.). Pesquisa Qualitativa em Estudos Organizacionais: Paradigmas, Estratégias e Métodos. São Paulo: Ed. Saraiva, 2006, p. 133-136.

HITO, S. C. Aprendizagem da Função Gerencial em Bancos. Dissertação (Mestrado). Universidade Presbiteriana Mackenzie, Centro de Ciências Sociais e Aplicadas, São Paulo, 2011.

HOLMAN, D.; EPITROPAKI, O.; FERNIE, S. Understanding learning strategies in the workplace: A factor analytic investigation. Journal of Occupational and Organizational Psychology, v. 74, n. 5, p. 675-681, 2001.

HOLMAN, D.; TOTTERDELL, P.; AXTELL, C.; STRIDE, C.; PORT, R.; SVENSSON, R.; ZIBARRAS, L. Job design and the employee innovation process: The mediating role of learning strategies. Journal of Business Psychology, v. 27, p. 177-191, 2012.

JESSUP, G. Outcomes: NVQs and the emerging model of education and training. London: The Falmer Press, 1991.

KING, N. Using templates in the thematic analysis of text. In: CASSELL, C.; SYMON, G. Essential guide to qualitative methods in organizational research. London: Sage Publications, 2004, p. 256270 .

KLEMP, G. O. The assessment of occupational competence. Report to the National Institute of Education, Washington, D.C., 1980.

LE BOTERF, G. Competénce et navigation professionnelle. Paris: Éditions d'Organisation, 1999. 
MARSICK, V. J.; WATKINS, K. E. Informal and Incidental Learning. New Directions for Adult and Continuing Education, v. 89, p. 25-34, 2001.

MCCLELLAND, D. C.; DAILEY, C. Improving officer selection for the foreign service. Boston: McBer, 1972.

OZAR, D. T. Building awareness of ethical standards. In: CURRY, L.; WERGIN, J. F. (Orgs.). Educating Professionals. San Francisco: Jossey-Bass, 1993, p. 148-177.

PANTOJA, M. J. Estratégias de aprendizagem no trabalho e percepções de suporte à aprendizagem contínua: Uma análise multinível. Tese (Doutorado) não publicada. Universidade de Brasília, Instituto de Psicologia, Brasília, 2004.

RUAS, R. L. Mestrado modalidade profissional: Em busca da identidade. Revista de Administração de Empresas, v. 43, n. 2, p. 55-63, 2003.

SCHÖN, D. The reflective practitioner: How professionals think in action. London: Temple Smith, 1983.

SCHRODER, H. M. Managerial competencies: The key to excellence. Dubuque: Kendall-Hunt, IA, 1989.

SILVA, A. B. Como os gerentes aprendem? São Paulo: Saraiva, 2009.

SILVA, L. L.; LISBOA, E. F.; FERREIRA, L. B.; VERSIANI, A. F.; SOUSA, P. R.; CORDEIRO, M. L. As instituições financeiras e sua relação com as fintechs no
Brasil. Economia e Gestão, v. 20, n. 55, p. 24-37, 2020.

SONNENTAG, S.; NIESSEN, C.; OHLY, S. Learning at work: training and development. In: COOPER, C. L.; ROBERTSON, I. T. (Eds.). International Review of Industrial and Organizational Psychology. London: John Wiley and Sons, 2004, v. 19, p. 249-289.

SPARR, J. L.; KNIPFER, K.; WILLEMS, F. How leaders can get the most out of formal training: The significance of feedback-seeking and reflection as informal learning behaviors. Human Resource Development Quarterly, v. 28, n. 1, p. 2954, 2017.

ULRICH, D. Recursos humanos estratégicos. São Paulo: Futura, 2000.

USHIRO, E. J.; BIDO, D. S. Estratégias de aprendizagem em função da finalidade para o aprendizado: Um estudo com trabalhadores da linha de produção de uma empresa do ramo automotivo. REAd Revista Eletrônica de Administração, v. 83, n. 1, p. 166-192, 2016.

WARR, P.; ALLAN, C. Learning strategies and occupational training. In: COOPER, C. L.; ROBERTSON, I. T. (Eds.). International Review of Industrial and Organizational Psychology. Chichester: Wiley, 1998, v. 13, p. 83-120.

WARR, P.; DOWNING, J. Learning strategies, learning anxiety and knowledge acquisition. British Journal of Psychology, v. 91, n. 3, p. 311-333, 2000.

\footnotetext{
${ }^{i}$ Sergio Santoro

Doutor em Administração de Empresas pela Universidade de Coimbra.

ii Diógenes de Souza Bido

Doutor em Administração de Empresas pela Universidade de São Paulo.
} 